\title{
Persistent long-term (1944-2015) ionosphere-magnetosphere associations at the area of intense seismic activity and beyond
}

\author{
T.L. Gulyaeva ${ }^{1}$, F. Arikan $^{2}$, I. Stanislawska ${ }^{3}$ \\ ${ }^{1}$ IZMIRAN, Kaluzskoe Sh. 4, Troitsk, Moscow 108840, Russia, gulyaeva@izmiran.ru \\ ${ }^{2}$ Department of EEE, Hacettepe University, Beytepe, Ankara 06800, Turkey, \\ arikan@hacettepe.edu.tr \\ ${ }^{3}$ Space Research Center, PAS, Barticka 18-A, Warsaw, Poland, stanis@ @bk.waw.pl
}

\begin{abstract}
Analysis of the earthquakes catalogues since 1944 reveals the area of the peak global earthquake occurrence in the Pacific Ocean southwards from the magnetic equator, in particular, at Australia. In the present study a long series of geomagnetic $a a$ indices gathered from two antipodal magnetic observatories at Melbourne (Australia) and Greenwich (UK) are compared with the monthly-hourly critical frequency, $f o F 2$, from the nearby ionosonde measurements at Canberra and Slough (Chilton) and Moscow (control site) since 1944 to 2015. The annual percentage occurrence of the positive ionosphere storms $\mathrm{W}$ index $\left(\mathrm{pW}^{+}\right)$and negative index $\left(\mathrm{pW}^{-}\right)$is determined. It is found that the occurrence of the ionosphere plasma depletion $\mathrm{pW}^{-}$of the instant $f o F 2$ as compared to the monthly median is well correlated with the $a a$ index at all three sites (cc > 0.85). The positive storm signatures of the plasma density enhancement $\mathrm{pW}^{+}$show high correlation with the geomagnetic activity $a a$ index at Slough $(\mathrm{cc}=0.68)$ and Moscow $(\mathrm{cc}=0.92)$ but drastic difference of missing correlation at Canberra $(\mathrm{cc}=0.06)$. It has been suggested that the frequent earthquake occurrence over Australia may produce the persistent significant ionosphere plasma enhancements at Canberra which disrupts balance between the ionosphere-magnetosphere activities.
\end{abstract}

Key words: Ionosphere critical frequency; ionospheric W index, geomagnetic $a a$ index; seismic activity

\section{Introduction.}

The early magnetograph records from two nearly antipodal sites at Greenwich $\left[51.5^{\circ} \mathrm{N}, 0^{\circ} \mathrm{E}\right]$ and Melbourne $\left[-37.8^{\circ} \mathrm{N}, 145^{\circ} \mathrm{E}\right]$ corresponding to the activity level at the invariant magnetic 
latitude of $50^{\circ}$ give a long series of geomagnetic $a a$ indices since 1868 . The $a a$ index derived from magnetic perturbation values at only two observatories (as distinct from the planetary ap index) experiences larger extreme values if either input site is well situated to the overhead ionospheric and/or field aligned current systems producing the magnetic storm effects. The annual values of the geomagnetic index $a a$ could be the resultant of two components: one originating from solar transient (or sporadic) activity which is in phase with the solar cycle; the other is related to recurrent solar drivers with peak in the declining phase (Feynman, 1982; Du, 2011a). The long-term trend of correlation of the annual $a a$ index with sunspot number has changed in 1958 revealing a 2-cycle periodicity superimposed on secular trends ( $\mathrm{Du}, 2011 \mathrm{~b})$. The earthquake related changes in surrounding geomagnetic field and ionosphere have been detected experimentally and justified with model simulations in (Liu et al. 2006; Kuo et al., 2011; Xu et al. 2013; Heki and Enomoto, 2015; and references therein) so the $a a$ index along with the other geomagnetic indices can serve as a tool to discriminate impact of geomagnetic storms and/or earthquakes on the ionosphere (Gulyaeva and Arikan, 2016).

One of the major discriminants of earthquake, EQ, effects on the ionosphere is the spatial range of the disturbance. Typically, geomagnetic storms affect large portions of globe after the anomalous changes in IMF-B, global electric currents and have patterns that can be recognized in the geomagnetic field. The co-seismic and post-seismic disturbances in the ionosphere can be observed locally or regionally depending on the type, magnitude and depth of the earthquake as indicated in various studies (Rishbeth, 2006; Kuo et al., 2011). The positive ionosphere storm is a regional-scale condition of the ionosphere occurring either during the geomagnetic disturbances or the tectonic events during which plasma densities are driven above values normally observed during quiet periods (Buonsanto, 1999; Immel and Manucci, 2013). The seismic-ionospheric links may be a source of the double excess of number of positive ionospheric storms at Kokubunji located at the region of enhanced seismic activity as compared to that at Boulder during 1985-2005 (Vijaya Lekshmi et al., 2011). The positive ionosphere anomalies are more effective than the negative ones for both storm and non-storm earthquake subsets which indicate on the EQ aftereffects producing rather increased plasma variability in the ionosphere than its decreasing process (Gulyaeva and Arikan, 2016).

It will be shown below that the earthquakes catalogues since 1944 reveal the area of the peak global earthquake occurrence in the Pacific Ocean southwards from the magnetic equator, and, in particular, at Australia. Accordingly, in the present study the ionosphere critical frequency, foF2, is analyzed from the ionosonde measurements at two antipodal observatories, Canberra and Slough (Chilton), located nearby the sites providing the magnetograph measurements for the $a a$ index, and 
one extra ionosonde at Moscow (control site) since 1944 to 2015. The daily-hourly-annual percentage occurrence of the positive ionospheric $\mathrm{W}$ index $\left(\mathrm{pW}^{+}\right)$and negative index $\left(\mathrm{pW}^{-}\right)$is determined. Magnitude of $\mathrm{W}$ index at each location varies from the quiet state, $\mathrm{W}= \pm 1$, to intense storm, $\mathrm{W}= \pm 4$ (Gulyaeva et al., 2008, 2011, 2013). Probability of occurrence, $\mathrm{pW}^{+}$, of the positive phase of ionosphere storm with foF 2 enhancement $(\mathrm{W}=3$ and $\mathrm{W}=4)$ and the negative phase, $\mathrm{pW}^{-}$ $(\mathrm{W}=-3$ and $\mathrm{W}=-4)$ is calculated in hourly-daily regime for the period of ionosonde observations from 1944 to 2015.

The global distribution of earthquakes and the data analysis method are provided in Sections 2 and 3, respectively. The paper ends with Conclusions section.

\section{Global distribution of earthquakes.}

Two Catalogues for more than 70 recent years of tectonic observations are used to produce estimates of the spatial distribution of earthquakes for the epoch of ionosonde service. First, we use earthquake events from the ISS.CAT for a period from 1944 to 1963 (Villasenor et al., 1997). This Catalogue contains hypocenters of earthquakes listed in the bulletins of the International Seismological Summary (ISS) from 1918 to 1963. In addition, the hypocenters listed in the bulletins of the British Association for the Advancement of Science (BAAS) Seismological Committee (the predecessor of the ISS) for 1914-1917 have also been included. The magnitude of earthquakes, M, is introduced by Gutenberg and Richter (1956) at the second half of $20^{\text {th }}$ century so the file ISS.CAT contains only hypocenters of earthquakes that have available phase arrival time data listed in tabular form in the ISS bulletins. Undetermined shocks and earthquakes reported by other agencies without arrival time data are not included in this file. When more than one hypocentral solution was produced for the same event (this practice was only used in the early years of the ISS) only the first solution has been listed, in order to avoid duplicate entries.

Second, the earthquake data from the global Catalogue of the Advanced National Seismic System (ANSS) provided by the Northern California Earthquake Data Center (NCEDS, 2014) are used for a period from 1964 to 2015. The composite Catalogue of earthquakes created by ANSS is a world-wide earthquakes catalog which is generated by merging the master earthquake catalogs from contributing ANSS member institutions and removing duplicate events, or non-unique solutions for the same event.

The global spatial distribution of earthquakes is irregular tending to denser earthquake occurrence in the Pacific region (Levin and Sasorova, 2012; Gulyaeva, 2014; Gulyaeva and Arikan, 
2016). The circum-Pacific "Ring of Fire" belt is generally accepted as the world's greatest earthquake zone, where about 90 percent of the world's largest earthquakes occur (Williams, 2016). The belt extends from the southern tip of South America, up along the coast of North America, across the Bering Strait, down through Japan, and into New Zealand. The actual pattern of the relative density of the spatial percentage distribution of 93591 earthquakes during 72 recent years (from 1944 to 2015) is demonstrated in Figure 1.

The regions of enhanced seismic activity (Figure 1) are observed along the tectonic plates boundaries (designated with the black points) at geographic longitudes from $90^{\circ}$ to $190^{\circ} \mathrm{E}$ and magnetic latitudes from $40^{\circ} \mathrm{S}$ to $40^{\circ} \mathrm{N}$, with dominant earthquake occurrence in the sub-equatorial region of the South magnetic hemisphere. The next appreciable zones of enhanced tectonic activity are revealed around the Far East Asia, the West coast of South America and the south part of Eurasian plate which also correspond to the tectonic plate boundaries. We note that most of the earthquakes are located within the limits of the closed magnetic field lines $\left( \pm 60^{\circ}\right.$ of magnetic latitudes). Some uncertainty in the EQs distribution in Figure 1 may be attributed to possible inclusion of earthquakes of arbitrary magnitudes in ISS.CAT (11 857 events for 1944-1963) while those from NCEDS catalogue with magnitudes equal to or greater than $\mathrm{M}=5.0$ (81 734 events for 1964-2015) comprise majority (87\%) of total number of earthquakes analyzed for the total period. Also, one could assume the more advanced technology of seismic records towards the end of $20^{\text {th }}$ century. Newer-the-less, the greater EQs occurrence around the Australian continent and availability of the long-term ionosonde observations in Australia suggest using these data for the analysis of possible seismic-ionospheric associations.

As follows from Figure 1, the Northern latitudes of Europe and Russia are beyond the regions of high seismicity where dominant positive ionosphere storm signatures have been detected (Gulyaeva et al., 2016). Thus, for investigating the seismic-ionospheric-magnetospheric associations we select the geomagnetic $a a$ index derived from the magnetometer observations at Australia and England, and three ionospheric stations: Canberra (Australia) in the area of enhanced earthquakes density, and two distant ionosondes at Slough (Chilton), England, and Moscow (control site), Russia. Complementary ionosonde measurements in Australia are used for mapping foF2 and Windex for a particular recent earthquake on July 8, 2016, as shown below.

\section{Data analysis.}


The critical frequency $f o F 2$, the square of which is proportional to the peak electron density $\mathrm{NmF2}$, is nearly always measurable with ionosondes. Day-to-day and hour-to-hour variability of $N m F 2$ involves different sources, with the most obvious cause, namely geomagnetic activity, unable to account for all observed variability so possible causes originating at lower levels require serious consideration (Rishbeth, 2006; Fotiadis and Kouris, 2006). The ionosonde measurements at three locations listed in the first three lines of Table 1 are used for calculations of the ionospheric weather $\mathrm{W}$-index in the present study for the total period of the ionosonde observations available from 1944 to 2015 .

In Gulyaeva et al. (2008), a segmented logarithmic scale of the ionospheric weather $W$ index is introduced for the different thresholds of change in $N m F 2$ for quantifying the ionosphere variability. The thresholds of the logarithmic ratios for $N m F 2$ and TEC are selected by equal increments in absolute values for the positive and negative logarithm magnitudes which correspond, however, to unequal linear deviations of the particular parameter from the median. As discussed in detail in Gulyaeva et al. $(2008 ; 2011), W= \pm 1$ corresponding to less than about $\pm 10 \%$ changes of $N m F 2$ regarding the median represents the quiet ionosphere state, $W= \pm 2\left(-30 \%<W^{\top}<-10 \%\right.$; $\left.10 \%<W^{+}<43 \%\right)$ denotes a moderate disturbance. When $W= \pm 3\left(-50 \%<W^{-}<-30 \% ; 43 \%<W^{+}<\right.$ $100 \%)$, a moderate ionospheric storm is imminent, and finally, $W= \pm 4\left(-100 \%\left\langle W^{\top}<-50 \% ; W^{+}\right\rangle\right.$ $100 \%)$ is the indicator of an intense ionospheric storm.

An example of the ionosphere variability is illustrated for the recent earthquake (EQ) occurred in South Australia (SA) at local winter on $8^{\text {th }}$ July, 2016, 09:40:51 h UT (nighttime, $17.9 \mathrm{~h}$ LT, solar zenith angle $\chi=99^{\circ}$ ), magnitude $M=5.2$, depth $\mathrm{D}=10 \mathrm{~km}$ at geographic coordinates $\left[32.44^{\circ} \mathrm{S}, 122.67^{\circ} \mathrm{E}\right]$ and geomagnetic coordinates $\left[41.8^{\circ} \mathrm{S}, 197.4^{\circ} \mathrm{E}\right]$. Figure $2 \mathrm{a}$ and $2 \mathrm{~b}$ represent foF 2 maps over Australia before the earthquake at 09 h UT and $10 \mathrm{~h}$ UT after EQ, respectively. Windex maps for the same hours are provided in Figure 2c and 2d. Data of 12 ionosondes listed in lines 3 to 14 of Table 1 (Figure 2a,b,c,d, crosses) are assimilated by the instantaneous foF2 mapping procedure (Stanislawska et al., 2000) for the day of earthquake and 27 preceding days. The quiet reference median foF 2 map is derived from the instant maps for -27 preceding days to serve for $\mathrm{W}$ index map production (Gulyaeva et al., 2008). While seismographs are capable to register an EQ at the very distant locations the ionosphere effects of EQ are registered within the limited area of about $1000 \mathrm{~km}$ radius near the EQ hypocentre (white star within yellow circle). Patterns of foF2 maps before and after EQ demonstrate significant difference but hour-to-hour variability of the ionosphere is more evident from $\mathrm{W}$-index maps. In particular, the cloud of positive electron density 
enhancement (red color) covering the eastern longitudes of the map prior to EQ event (Figure 2c) has propagated through the most part of W-index map after the EQ (Figure 2d). Canberra ionosonde data used for the long-term analysis and those for Perth ionosonde located nearby EQ hypocenter (white cycles) will be used for a comparison of the ionosphere records near the EQ with those at two distant ionosondes at Chilton and Moscow.

Figure $3 \mathrm{a}, \mathrm{b}$ presents $f_{o F} 2$ critical frequency and results of $\mathrm{W}$-index calculation at four ionospheric stations listed in lines 1 to 4 of Table 1. The interplanetary state characteristics (Figure 3c, courtesy: OMNI), and the $a a$ index (Figure 3d) are also provided. The OMNI's magnitude of the Interplanetary Magnetic Field, B, is enhanced $4 \mathrm{~h}$ prior to EQ but it is decreasing after the EQ, the IMF component $\mathrm{Bz}<0$ and the high speed solar wind $(\mathrm{V}>560 \mathrm{~km} / \mathrm{s})$ are observed during several hours embracing EQ time (Figure 3c, red line). The earthquake EQ-SA has happened at the peak of the geomagnetic sub-storm observed at high latitudes (Auroral Electrojet index $A E=1350 \mathrm{nT}$ ) and mid-latitudes (geomagnetic indices $k p=4$, $a p=27 \mathrm{nT}, a a=67 \mathrm{nT}$ ), while the ring current conditions at the equatorial zone are quiet $(D s t=-23 \mathrm{nT})$. Figure 3a,b demonstrate persistent negative ionosphere storm, $\mathrm{W}^{-}$, for the local summer pre-noon hours 9.6 LT (EQ-SA time) at Chilton and noon $12.2 \mathrm{~h} \mathrm{LT} \mathrm{(EQ-SA} \mathrm{time)} \mathrm{at} \mathrm{Moscow} \mathrm{while} \mathrm{positive} \mathrm{aftereffect} \mathrm{of} \mathrm{the} \mathrm{ionization}$ enhancement, $\mathrm{W}^{+}$, is seen during local winter nighttime hours (EQ-SA time) at $17.4 \mathrm{LT}$ at Perth $\left(\chi=97^{\circ}\right)$ and after 19.6 LT $\left(\chi=125^{\circ}\right)$ at Canberra. The ionosphere behavior at Perth and Canberra shows typical pattern of the positive ionosphere EQ aftereffect statistically examined in (Gulyaeva and Arikan, 2016).

Close link of the negative ionosphere disturbances at Moscow with the geomagnetic $a a$ index has been pointed out earlier for a period of the ionosonde observations from 1951 to 1988 (Gulyaeva and Gulyaev, 1989; Gulyaeva, 1995). Expecting a similar linkage for the positive and negative $\mathrm{W}$ index variations at three selected sites, the annual counts of the negative ionosphere storm hours $\left(\mathrm{W}^{-}=-3\right.$ and $\left.\mathrm{W}^{-}=-4\right)$ and the positive ionosphere storm hours $\left(\mathrm{W}^{+}=3\right.$ and $\left.\mathrm{W}^{+}=4\right)$ are calculated from the monthly-hourly tables of foF2 for Canberra, Chilton (Slough) and Moscow from 1944 to 2015. The results are plotted in Figure 4 along with the $a a$-index for the same period. The negative ionosphere storm hours are dominant for all three locations over the positive periods. The results for Canberra show minimum positive storm hours and maximum negative storm hours during 1944 to 1963 as compared with two other locations. However, the total counts of the storm hours could be affected by neglecting the foF 2 ionosonde measurements which are missing due to physical causes such as F-spread, the blanketing sporadic Es layer occurrence, or technical reasons. 
The more rigorous data processing involves evaluation of the daily-hourly-annual percentage occurrence of positive ionospheric $\mathrm{W}$ index $\left(\mathrm{pW}^{+}\right)$and negative index $\left(\mathrm{pW}^{-}\right)$normalized by the total annual hourly ionosonde measurements excluding missed observations. The results of annual percentage occurrence and the 11-years smoothed $\mathrm{pW}^{+}$and $\mathrm{pW}^{-}$for Canberra for each year from 1944 to 2015 are presented in Figure 5 as well as the annual and the 11-years smoothed $a a$ index from 1868 to 2015. The coherence between the geomagnetic and ionospheric indices is better pronounced with the 11-years smoothed results, in particular, the negative ionosphere storm variability in Canberra is similar to $a a$ index variations while the positive storm occurrence looks less related with the $a a$ index.

The regression of the ionosphere percentage storm occurrence results for each year from 1944 to 2015 are plotted against $a a$ index in Figure 6 (points). The 11 -years smoothed $\mathrm{pW}^{+}$and $\mathrm{pW}^{-}$ are also presented (cycles). The correlation proves to be high for the negative ionosphere storm signatures at all three sites (bottom panel). However, the positive storm signatures (top panel) at Canberra are not correlated with geomagnetic activity (the correlation coefficient $\mathrm{cc}=0.06$ ). One can assume that the frequent earthquake occurrence over Australia (regional feature) may produce the persistent significant ionosphere plasma enhancements $\mathrm{pW}^{+}$at Canberra (over the same region) which disrupts balance between the ionosphere-magnetosphere activities.

\section{Conclusions.}

Analysis of the earthquakes catalogues since 1944 to present reveals the area of the peak global earthquake occurrence in the Pacific Ocean southwards from the magnetic equator, in particular, at Australia. The ionospheric weather $\mathrm{W}$ indices are calculated from the foF 2 critical frequency from 1944 to 2015 at Canberra (Australia), Chilton (Slough) - the antipodal site in UK, and Moscow (control site), two latter located in the Northern Hemisphere beyond the enhanced tectonic activity.

The foF 2 variability is compared with a long time series of geomagnetic $a a$ indices gathered from two antipodal magnetic observatories at Melbourne (Australia) and Greenwich (UK). The annual counts of the $\mathrm{W}$ index storm hours and the percentage occurrence of the positive ionosphere storms $\mathrm{W}$ index $\left(\mathrm{pW}^{+}\right)$and negative index $\left(\mathrm{pW}^{-}\right)$is determined. It is found that the occurrence of the ionosphere plasma depletion $\mathrm{pW}^{-}$of the instant $f o F 2$ as compared to the monthly median is well correlated with the $a a$ index at all three sites ( $\mathrm{cc}>0.85)$. The positive storm signatures of the plasma density enhancement $\mathrm{pW}^{+}$show high correlation with the geomagnetic activity $a a$ index at Slough 
$(\mathrm{cc}=0.68)$ and Moscow $(\mathrm{cc}=0.92)$ but drastic difference of missing correlation at Canberra $(\mathrm{cc}=$ $0.06)$.

It has been suggested that the frequent earthquake occurrence over Australia may produce the persistent significant ionosphere plasma enhancements at Canberra which disrupts balance between the ionosphere-magnetosphere activities. The results confirm that the ionospheric weather W index presents a powerful tool for investigating the seismic-ionospheric-geomagnetic associations.

\section{Acknowledgements}

Catalogue of earthquake hypocenters for 1914-1963 is provided by US Geological Servey http://earthquake.usgs.gov/data/iss_summ.php. Earthquake data products for this study were accessed through the Northern California Earthquake Data Center (NCEDC), doi:10.7932/NCEDC at http://www.quake.geo.berkeley.edu/anss/catalog-search.html. Earthquake data on 7.08.2016 are provided by RAS Geophysical Servey http:/www.ceme.gsras.ru/cgi-bin/ceme/equakes.pl/. The PRIME251 foF2 instantaneous maping software is provided by SRC http://rwc.cbk.waw.pl/. Geomagnetic $a a$ index and ionospheric foF2 data for Slough (Chilton) are provided by UK Solar System Data Center http://www.ukssdc.ac.uk/wdcc1/. The ionospheric foF2 data for Australian ionosondes are provided by IPS http://www.sws.bom.gov.au/World_Data_Centre/. Moscow foF2 data and the ionospheric $\mathrm{W}$ index for network of the ionospheric stations are provided by IZMIRAN http://www.izmiran.ru/services/iweather/. This study is partly supported by TUBITAK EEEAG 115E915. The important comments of two Referees are gratefully appreciated by the authors.

\section{References}

Buonsanto, M.J., 1999. Ionospheric storms - A review. Space Sci. Rev. 88, 563-601, DOI:10.1023/A:1005107532631.

Devi, M., Barbara, A.K., Oyama, K.-I., Chen, Ch.-H., 2014. Earthquake induced dynamics at the ionosphere in presence of magnetic storm. Adv. Space Res. 53, 609-618. DOI: 10.1016/j.asr.2013.11.054.

Du, Z.L., 2011a. The correlation between solar and geomagnetic activity - part 1: two-term decomposition of geomagnetic activity. Ann. Geophys. 29, 1331-1340, DOI:10.5194/angeo-291331-2011. 
Du, Z.L., 2011b. The correlation between solar and geomagnetic activity - part 2: long-term trend. Ann. Geophys. 29, 1341-1348, DOI:10.5194/angeo-29-1341-2011, 2011.

Feynman, J., 1982. Geomagnetic and solar wind cycles, 1900-1975. J. Geophys. Res. 87, 61536162.

Fotiadis, D.N., Kouris, S.S., 2006. A functional dependence of foF2 variability on latitude. Adv. Space Res. 37, 1023-1028, DOI:10.1016/j.asr.2005.02.054.

Gulyaeva, T.L., 1995. Half-century of radio probing of the ionosphere. In Proc. '100 Years of Radio', Conference Publication 411, IEE, UK, 231-234.

Gulyaeva, T.L., 2014. Association of seismic activity with solar cycle and geomagnetic activity. Develop. Earth Sci. 2, 14-19. Available from: http://www.seipub.org/des/.

Gulyaeva, T.L., Gulyaev, R.A., 1990. Restoration of the time-series in solar-terrestrial physics. Doklady Akademii Nauk USSR, 314, No.3, 581-583 (in Russian).

Gulyaeva, T.L., Stanislawska, I., Tomasik, M., 2008. Ionospheric weather: Cloning missed foF2 observations for derivation of variability index. Ann. Geophys., 26, N.2, 315-321, www.anngeophys.net/26/315/2008/.

Gulyaeva, T.L., Arikan, F., Stanislawska, I., 2011. Inter-hemispheric Imaging of the Ionosphere with the upgraded IRI-Plas model during the space weather storms, Earth, Planets, Space, 63, 929-939, DOI:10.5047/eps.2011.04.007.

Gulyaeva, T.L., Arikan, F., Hernandez-Pajares, M., Stanislawska, I., 2013. GIM-TEC adaptive ionospheric weather assessment and forecast system. J. Atmos. Solar-Terr. Phys., 102, 329-340, DOI:10.1016/j.jastp.2013.06.011.

Gulyaeva, T.L., Arikan, F., 2016. Statistical discrimination of global post-seismic ionosphere effects under geomagnetic quiet and storm conditions. Geomatics, Natural Hazard, Risk, http://dx.doi.org/10.1080/19475705.2016.1246483.

Gulyaeva, T.L., Arikan, F., Stanislawska, I., Poustovalova, L.V., 2016. Global distribution of zones of enhanced risk for the ionospheric weather. J. Geography, Earth, Environ. Int., 4(1), 1-13, DOI:10.9734/JGEESI/2016/20488, http://sciencedomain.org/issue/1438.

Gutenberg, B., Richter, C.F., 1956. Magnitude and energy of earthquakes. Ann. Geofis., 9, 1-15.

Heki, K., Enomoto,Y., 2015. Mw dependence of the preseismic ionospheric electron enhancements. J. Geophys. Res., Space Physics, 120, 7006-7020, DOI: 10.1002/2015JA021353.

Immel, T.J., Manucci, A.J., 2013. Ionospheric redistribution during the geomagnetic storm. $J$. Geophys. Res. Space Phys., 118, 7928-7939, DOI:10.1002/2013JA018919. 
Kuo, C.L., Huba, J.D., Joyce, G., Lee, L.C., 2011. Ionosphere plasma bubbles and density variations induced by pre-earthquake rock currents and associated surface charges, J. Geophys. Res., 116, A10317, doi:10.1029/2011JA016628.

Levin, B.W., Sasorova, E.V., 2012. Seismicity of the Pacific Region: global feature detection. Moscow, Janus-K, 307pp. (in Russian)

Liu, J.Y., Chen, C.H., Chen, Y.I., Yen, H.Y., Hatton, K., Yumoto, K., 2006. Seismo-geomagnetic anomalies and $M \geqslant 5.0$ earthquakes observed in Taiwan during 1988-2001. Phys. Chem. Earth. Part A/B/C. 31, 215-222, DOI: 10.1016/j.pce.2006.02.009.

NCEDC, 2014. Northern California Earthquake Data Center. UC Berkeley Seismological Laboratory, Dataset. DOI: 10.7932/NCEDC.

Rishbeth, H., 2006. F-region links with the lower atmosphere? J. Atmos. Solar-Terr. Phys., 68, 469478, DOI:10.1016/j.jastp.2005.03.017.

Stanislawska, I., Juchnikowski, G., Hanbaba, R., Rothkael, H., Sole, G., Zbyszynski, Z., 2000. COST 251 recommended instantaneous mapping model of ionospheric characteristics — PLES, Phys. Chem. Earth, Part C: Solar, Terrestrial \& Planetary Science, 25, 4, 291-294, DOI:10.1016/S1464-1917(00)00019-2.

Vijaya Lekshmi, D., Balan, N., Tulasi Ram, S., Liu, J.Y., 2011. Statistics of geomagnetic storms and ionospheric storms at low and mid latitudes in two solar cycles, J. Geophys. Res. Space Physics. 116, A11328, DOI:10.1029/2011JA017042.

Villasenor, A., Bergman, E.A., Boyd, T.M., Engdahl, E.R., Frazier, D.W., Harden, M.M., Orth, J.L., Parkes, R.L., Shedlock, K.M., 1997. Toward a comprehensive catalog of global historical seismicity, Eos Trans. AGU, 78, No. 50, 581-588.

Williams, M., 2016. What is the Pacific "Ring of Fire"? http://www.universetoday.com/59341/pacific-ring-of-fire/.

Table 1. Geographic and geomagnetic latitude and longitude of ionosonde foF2 data used in the analysis. The geomagnetic coordinates are calculated by the International Geomagnetic Reference Field (IGRF) for the year 2016 at 300 km height. 


\begin{tabular}{|l|l|l|l|l|l|}
\hline nn & Station & $\begin{array}{l}\text { Glat } \\
\text { deg. N }\end{array}$ & $\begin{array}{l}\text { Glon } \\
\text { deg. E }\end{array}$ & $\begin{array}{l}\text { Mlat } \\
\text { deg. N }\end{array}$ & $\begin{array}{l}\text { Mlon } \\
\text { deg. E }\end{array}$ \\
\hline 1 & Chilton (Slough) & 51.6 & 358.7 & 53.7 & 83.8 \\
\hline 2 & Moscow & 55.5 & 37.3 & 51.2 & 121.7 \\
\hline 3 & Canberra & -35.3 & 149.1 & -42.3 & 227.1 \\
\hline 4 & Perth & -32.0 & 115.9 & -41.7 & 189.5 \\
\hline 5 & Darwin & -12.2 & 130.9 & -21.2 & 204.6 \\
\hline 6 & Townsville & -19.7 & 146.9 & -27.1 & 222.1 \\
\hline 7 & Learmonth & -21.8 & 114.1 & -31.5 & 187.1 \\
\hline 8 & Brisbane & -27.5 & 152.9 & -34.1 & 229.7 \\
\hline 9 & Norfolk & -29.0 & 168.0 & -33.5 & 245.8 \\
\hline 10 & Camden & -34.0 & 150.7 & -40.8 & 228.6 \\
\hline 11 & Hobart & -42.9 & 147.2 & -50.1 & 226.8 \\
\hline 12 & MacQuarue & -54.5 & 159.0 & -59.8 & 244.4 \\
\hline 13 & Casey & -66.3 & 110.5 & -76.1 & 185.0 \\
\hline 14 & Scott Base & -77.9 & 166.8 & -79.0 & 288.7 \\
\hline
\end{tabular}

\section{Figure captions.}

Fig. 1. Global distribution of earthquakes during 1944 to 2015.

Fig. 2. Regional ionospheric maps before and after the South Australian (SA) earthquake (EQ) M5.2 on $8^{\text {th }}$ July, 2016, 09:40:51 h UT: (a) foF2 at 09:00 h UT; (b) foF2 map at 10:00 h UT; (c) $\mathrm{W}$-index map at 09:00 h UT; (d) W-index map at 10:00 h UT.

Fig. 3. Space environment during the day of South Australian earthquake on $8^{\text {th }}$ July, 2016, shown in Figure 2: (a) Daily-hourly ionospheric $f o F 2$ critical frequency and 27-preceding days running median in Perth, Canberra, Chilton and Moscow; (b) W index; (c) Interplanetary Magnetic Field and solar wind velocity; (d) 3-h aa index.

Fig. 4. Annual $a a$ index and the ionospheric W storm hours counts in Canberra, Chilton (Slough) and Moscow from 1944 to 2015.

Fig. 5. Annual and 11-years smoothed $a a$ index from 1848 to 2015 and percentage occurrence of the positive and negative ionospheric storm hours in Canberra from 1944 to 2015. 
Fig. 6. Correlation analysis of the positive and negative ionosphere foF2 variability with geomagnetic aa index in Canberra, Chilton (Slough) and Moscow from 1944 to 2015.

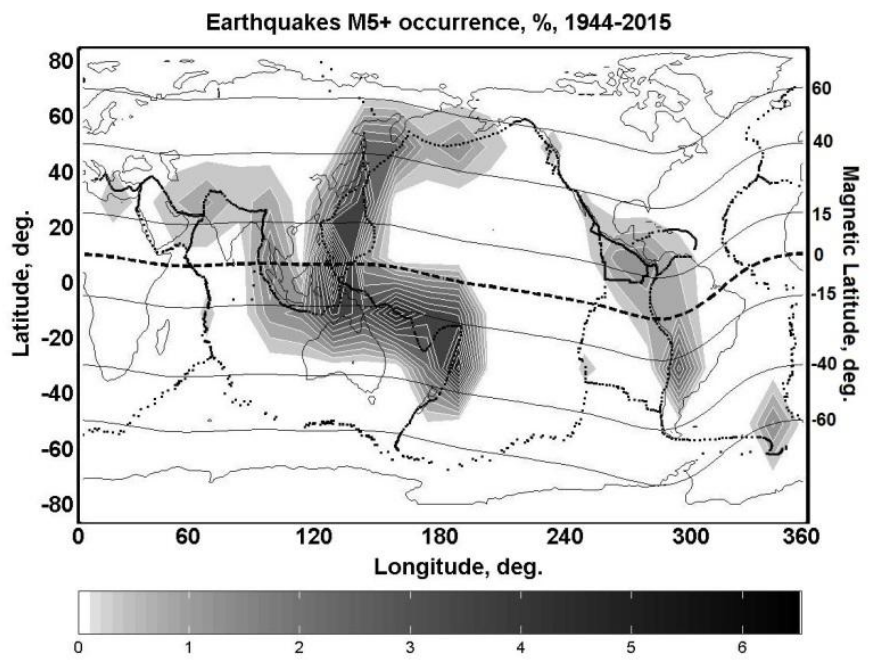

Fig. 1. Global distribution of earthquakes during 1914 to 2015. 

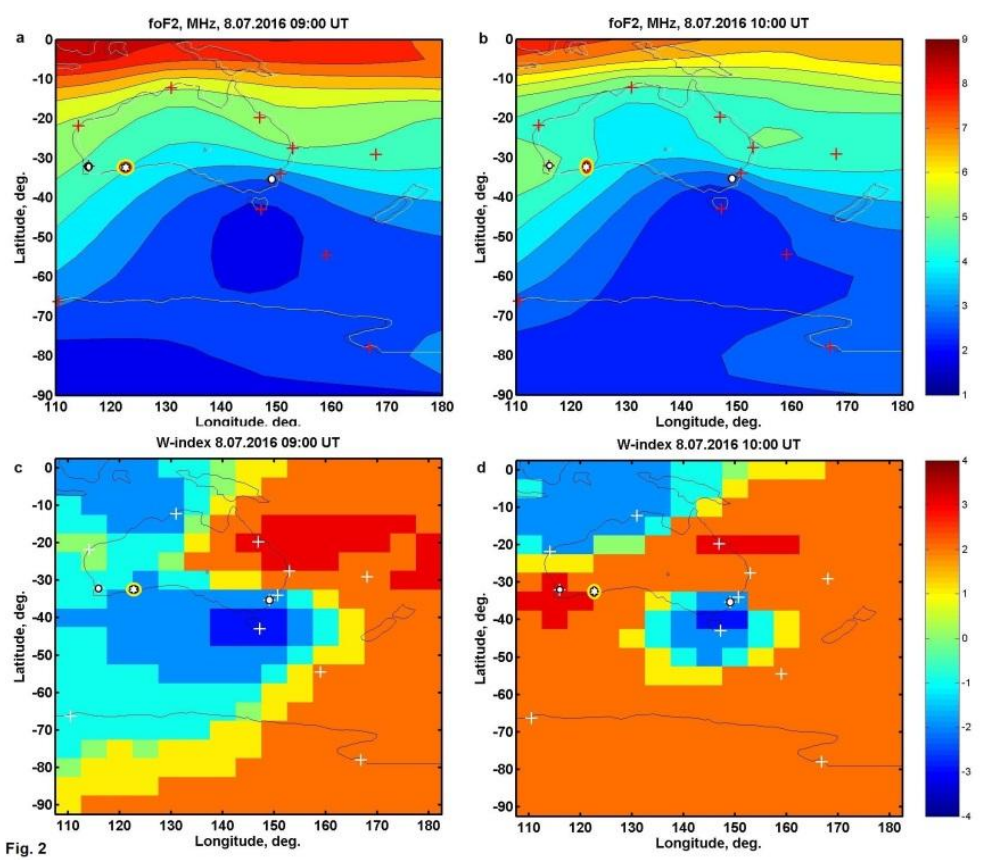

Fig. 2. Regional ionospheric maps before and after the South Australian (SA) earthquake (EQ) M5.2 on $8^{\text {th }}$ July, 2016, 09:40:51 h UT: (a) foF2 at 09:00 h UT; (b) foF2 map at 10:00 h UT; (c) W-index map at 09:00 h UT; (d) W-index map at 10:00 h UT. 

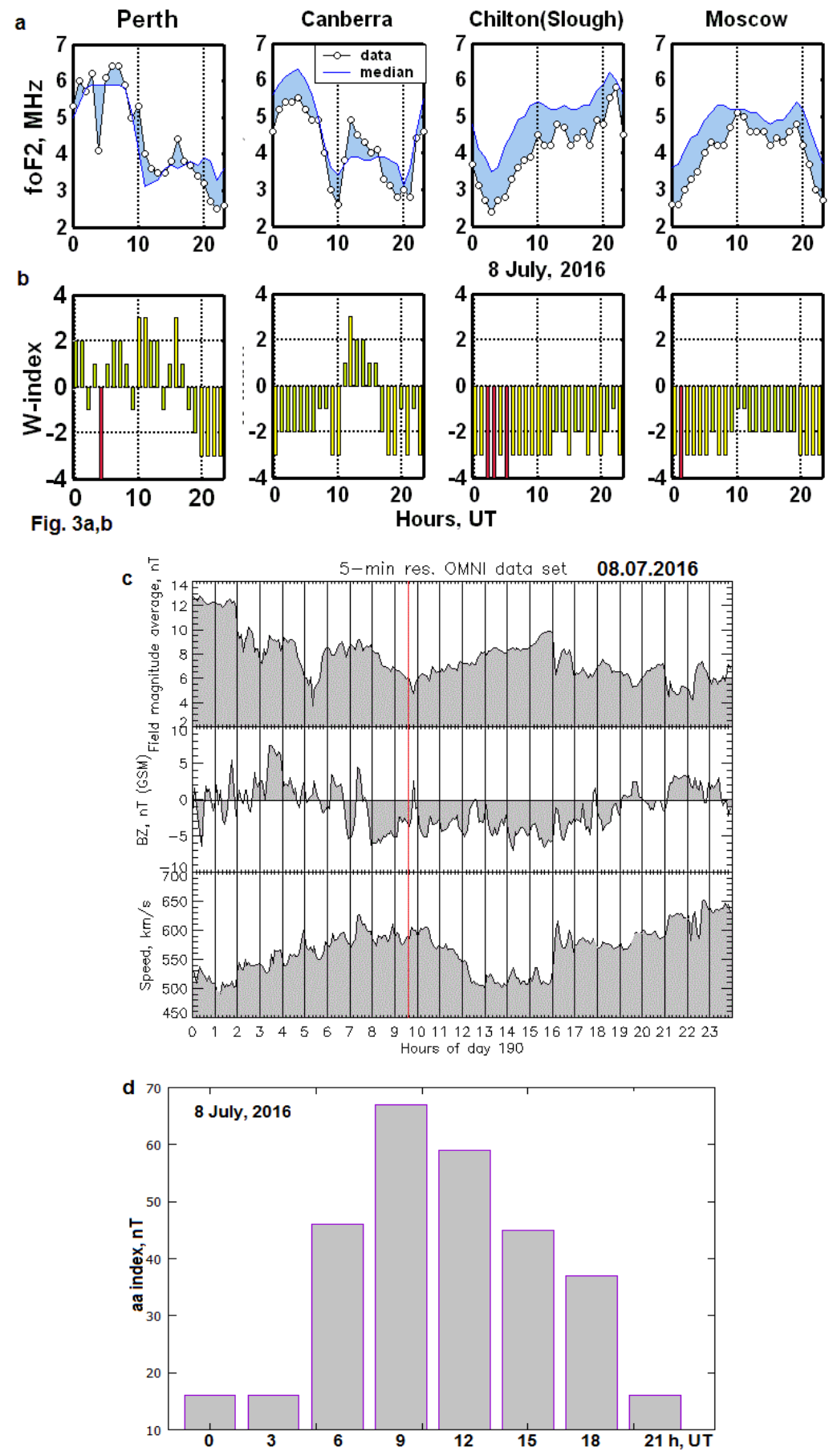

Fig. 3. Space environment during the day of South Australian earthquake on $8^{\text {th }}$ July, 2016, shown in Figure 2: (a) Daily-hourly ionospheric $f o F 2$ critical frequency and 27-preceding days running median in Perth, Canberra, Chilton and Moscow; (b) W index; (c) Interplanetary Magnetic Field and solar wind velocity; (d) 3-h aa index. 


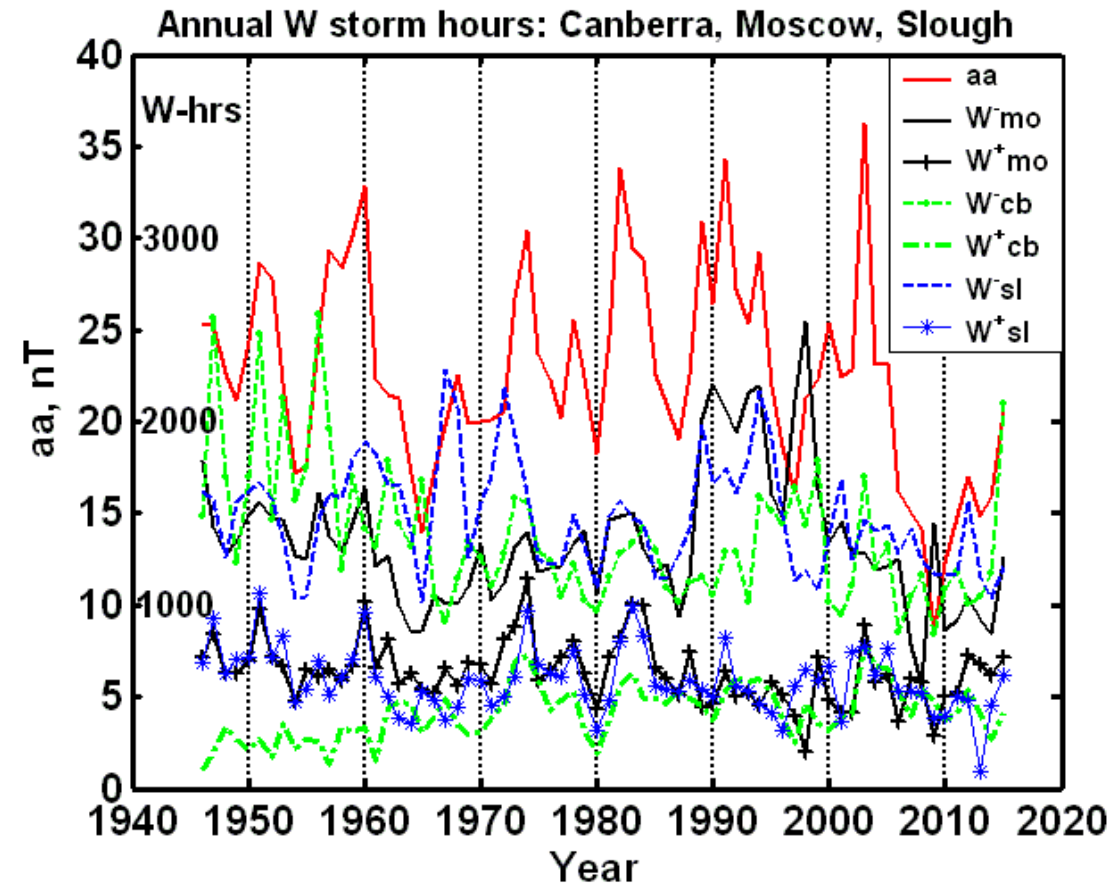

Fig. 4. Annual $a a$ index and the ionospheric W storm hours counts in Canberra, Chilton (Slough) and Moscow from 1944 to 2015. 


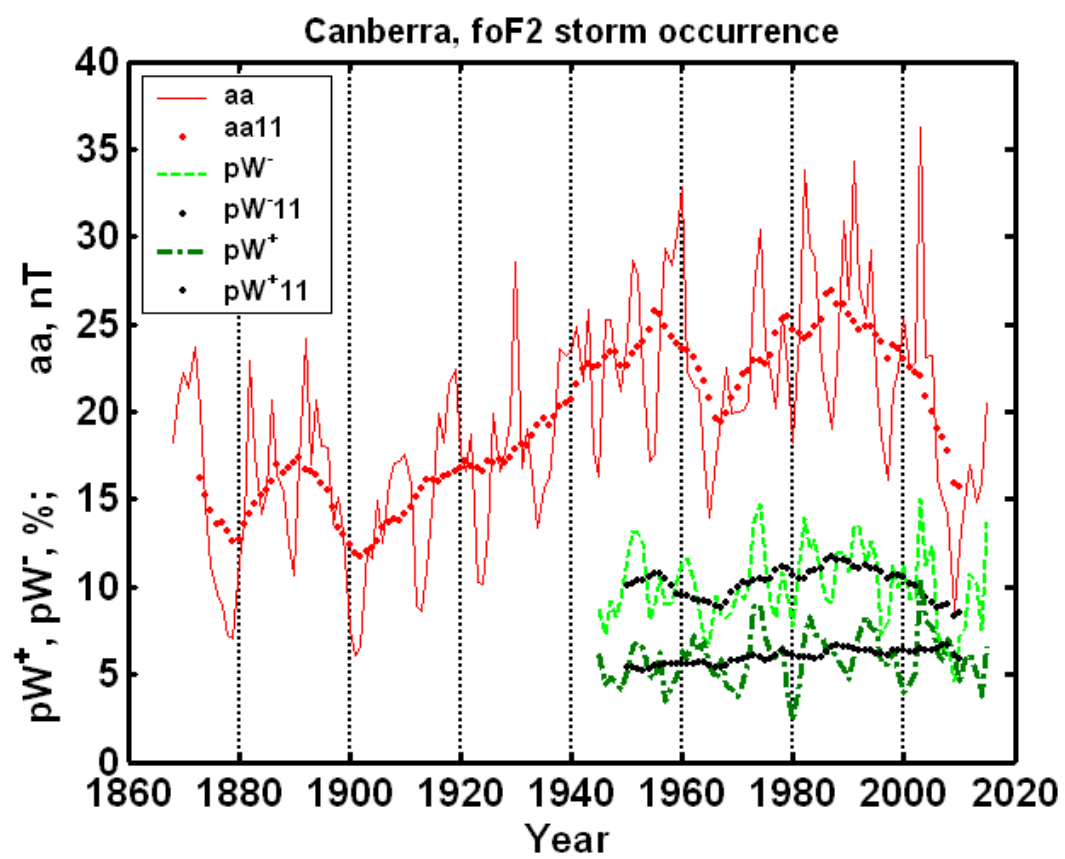

Fig. 5. Annual and 11-years smoothed $a a$ index from 1848 to 2015 and percentage occurrence of the positive and negative ionospheric storm hours in Canberra from 1944 to 2015. 

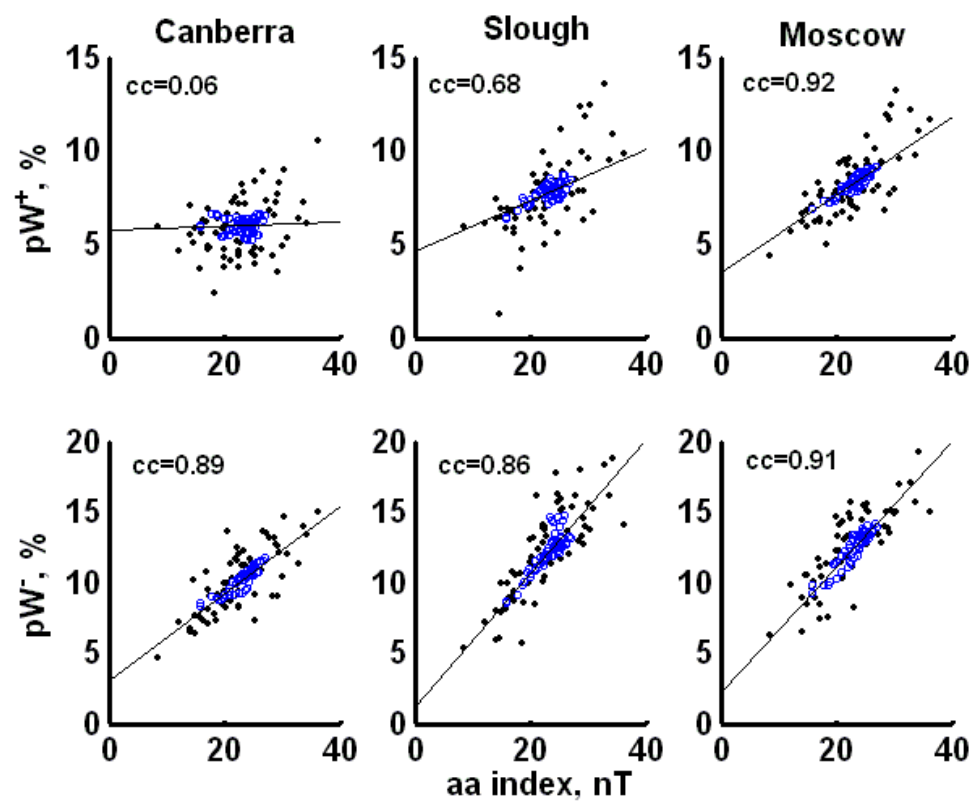

Fig. 6. Correlation analysis of the positive and negative ionosphere foF2 variability with geomagnetic a index in Canberra, Chilton (Slough) and Moscow from 1944 to 2015 